\title{
LIVRO DIDÁTICO DIGITAL DE INGLÊS: UM GÊNERO NOVO?
}

\section{THE DIGITAL ENGLISH COURSE BOOK: A NEW GENRE?}

Renato Caixeta SILVA ${ }^{1}$

Resumo: Este artigo focaliza o denominado livro didático digital de inglês, o qual vem sendo divulgado pelas editoras para uso em diversos contextos de ensino. O objetivo é refletir sobre a seguinte questão: o livro didático digital de inglês é ou não um gênero discursivo novo, uma vez que é veiculado em ambiente diferente do tradicional livro didático impresso? O estudo é baseado nas ideias de Bakhtin sobre gênero do discurso e da Escola de Sidney, está ancorada na Linguística Sistêmico-Funcional e nas ideias sobre gêneros digitais defendidas por Araújo (2016). Parte-se da premissa de que o livro didático tradicional impresso é um gênero discursivo, para se analisar um corpus constituído de amostras disponíveis em páginas de editoras nacionais na internet e informações das editoras sobre livros didáticos digitais. A análise do corpus mostra que o denominado livro didático digital de inglês mostrado nos sítios eletrônicos das editoras, e assim definido por elas, é o livro didático impresso em versão digitalizada, com as mesmas características do material já conhecido, não mudando as relações entre os usuários, o conteúdo e nem mesmo o modo de composição. Além disso, o acesso ao livro didático digital é limitado a pessoas que adquirem o livro impresso, não podendo ser usado independente ou em substituição ao impresso. Assim, não se pode afirmar que o livro didático digital traga novas formas de ensinar e aprender com uso de tecnologias digitais ou inserido no meio digital, pois ele não promove nova organização da vida e do fazer do professor ou do estudante na esfera educacional.

Palavras-chave: Bakhtin. Escola de Sidney. Gêneros Discursivos. Livro didático digital de inglês.

\begin{abstract}
This article focuses on the so-called digital English coursebook, which has been disclosed by publishers for use in several contexts. The aim is to reflect upon the following question: is the digital English coursebook a new genre or not, as it is present in a different environment in comparison with the traditional printed coursebook. The hypothesis assumed is a negative answer to the research question. The study is based on Bakhtin's ideas about genres as well as the ideas defended by the Sydney School of genre studies, this one anchored at Systemic-Functional Linguistics, and the ideas about digital genres defended by Araújo (2016). From the idea that the printed English coursebook is a discursive genre, the corpus to be analyzed is composed of available samples present in Brazilian editors' websites and the editors' sayings about the digital coursebook. The analysis confirms the hypothesis, as it shows the digital English coursebook is, in fact, the printed one in a digitalized version with the same well-known characteristics, not changing in terms of relations between users, nor in content, or in composition. Besides, the access to the digital coursebook is limited to those people who acquire the printed coursebook. So, it is not possible to say the digital coursebook brings new ways of teaching and learning for it does not promote a new organization in neither the teachers' nor the students' lives in education.
\end{abstract}

Key-words: Bakhtin. Sidney School. Genres. English Digital Coursebooks.

\footnotetext{
1 Centro Federal de Educação Tecnológica de Minas Gerais (CEFET), Belo Horizonte, Minas Gerais, Brasil; rencaixe@yahoo.com.br; http://orcid.org/0000-0003-3274-3071
} 


\begin{abstract}
"O que me parece fundamental para nós, hoje, mecânicos ou físicos, pedagogos ou pedreiros, marceneiros ou biólogos é a assunção de uma posição crítica, vigilante, indagadora, em face da tecnologia. Nem, de um lado, demonologizála, nem, de outro, divinizá-la." (Paulo Freire)
\end{abstract}

\title{
Introdução
}

A relação entre livros didáticos de línguas e gêneros discursivos não é algo novo nos estudos de linguagem. Nas duas últimas décadas, diferentes trabalhos acadêmicos têm focado o tema com base nas diversas teorias de gênero e de ensino de línguas, sendo os principais temas a consideração do livro didático como gênero discursivo, a inserção de gêneros em geral ou de determinados gêneros em livros didáticos e gêneros discursivos que se referem ou se ligam ao livro didático.

Este material de ensino é considerado gênero do discurso, por exemplo, em Silva (2015), em que se mostra como o livro didático de inglês, sendo um gênero discursivo multimodal, pode ser promotor de multiletramentos. Outro exemplo anterior é o trabalho de Buzen e Rojo (2005), em que os autores argumentam em favor do entendimento do livro didático de português como um gênero na perspectiva dos estudos bakhtinianos em contraposição a uma visão desse material de ensino como suporte de textos exemplares de vários gêneros. Mais sobre esses trabalhos será apresentado adiante neste artigo.

Há também trabalhos acadêmicos que enfatizam os gêneros presentes em livros didáticos, consequentemente propostos para o ensino da língua estudada. $\mathrm{Na}$ obra organizada por Dias e Dell'Isola (2012), por exemplo, vários são os capítulos que tratam da inserção de gêneros textuais e atividades correlacionadas em livros didáticos de inglês e de português língua estrangeira. Pode ser mencionada, ainda, a dissertação de mestrado defendida por Valente (2012), em que a autora analisa como uma coleção didática de inglês para o ensino médio brasileiro operacionaliza o ensino de leitura e escrita via gêneros, mostrando que a integração dessas habilidades escritas acontece mais por meio do tema tratado nos textos e unidades do que pelos gêneros escolhidos para trabalho sistemático. Também, a dissertação de Silva (2006) observou a presença ou ausência de gêneros discursivos em livros didáticos de inglês destinados a alunos iniciantes. Nesta pesquisa, a autora detectou, em seu corpus, poucos gêneros da escrita representados nesses livros didáticos, contrastando com uma presença mais notada de tipos textuais (narrativos, argumentativos, descritivos e injuntivos). 
Consideram-se, ademais, trabalhos acadêmicos que analisam gêneros relacionados aos livros didáticos, como em Silva (2012a), em que anúncios de catálogos, quartas capas e apresentações de manuais do professor são analisados enquanto gêneros que materializam o discurso de produtores e contribuem para a construção de representações acerca do livro didático de inglês. Outros trabalhos na mesma perspectiva mostram o uso da língua em quartas capas de livros didáticos (SILVA, 2016a) e em manuais destinados a docentes usuários de determinados livros didáticos (SILVA, 2012b).

Recentemente, tem sido frequente a menção a livros didáticos digitais na mídia, em materiais de divulgação e em livros didáticos impressos. Sítios eletrônicos de editoras convidam professores e alunos a acessarem exemplares (na maioria das vezes, trechos) de livros didáticos digitais, com promessas de mais motivação e interação no ensino e na aprendizagem. Ao se abrir uma obra didática impressa mais recente, independente do componente curricular, inclusive língua estrangeira, é comum o aluno ou o professor encontrarem avisos estimulando-os a visitar portais eletrônicos das editoras e seguirem instruções para acesso a conteúdos exclusivos e download de livros digitais. Tais avisos, em alguns casos, dão a ligeira impressão para professores, alunos e pesquisadores, de que o livro digital seria outro gênero, diferente do livro didático impresso, uma novidade para a aprendizagem do idioma. O exemplo a seguir (Figura 1) foi retirado de uma obra com essa característica. 
- Livro didático digital de inglês: um gênero novo?

Figura 1. Aviso destinado a estudantes para acesso a portal eletrônico e livro digital ${ }^{2}$

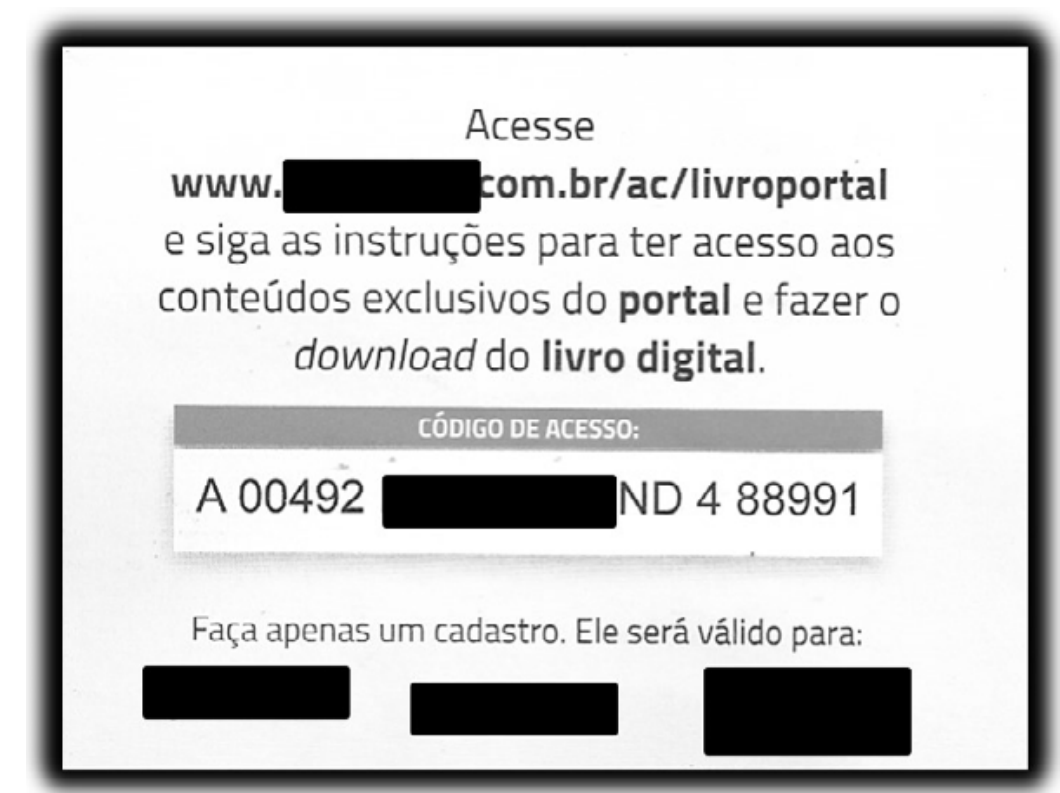

Fonte: MILITELLO, A. L. Obra coletiva concebida, desenvolvida e produzida pela Editora 2. ed. São Paulo: 2014, página inicial

Neste caso, especificamente, tem-se a editora instigando o aluno a acessar o portal para ter em sua máquina (computador, tablet, ou outro dispositivo) o livro digital, como se ele fosse mais um material que pudesse ser utilizado para aprender, pois são mencionados "conteúdos exclusivos". Esse acesso é restrito ao aluno que comprou o livro impresso, uma vez que o acesso só é possível com o código apresentado. Numa tentativa pessoal, como pesquisador, utilizando-me do código de aluno, não obtive sucesso, o que leva a crer que o acesso é também limitado ao ano em que o aluno estiver usando aquele livro adotado pela escola.

O objetivo deste artigo, então, é responder à seguinte pergunta de investigação: o livro didático digital de inglês pode ser entendido como um gênero discursivo novo uma vez que é veiculado em ambiente diferente do tradicional livro didático impresso? Acredita-se que o livro didático digital de inglês possa ser tão somente o livro impresso exposto na internet de maneira a não configurar um novo gênero.

Este trabalho está ligado a dois projetos desenvolvidos pelo pesquisador na área de Linguística Aplicada e Estudos de Linguagens: Aspectos da Avaliação e do Uso de

2 Em todo o artigo, o recurso de retângulo preto foi utilizado nas imagens e suas referências de fonte para não se mostrar os nomes de editoras e ou livros didáticos por questões éticas. 
Materiais Didáticos para o Ensino de Línguas e Discursos sobre o Ensinar e o Aprender. Com relação ao primeiro projeto, este estudo se propõe a mostrar aspectos do que vem a ser um livro didático digital de inglês, o que pode direcionar a visão dos professores e pesquisadores sobre tal livro e com isso interferir na avaliação ou no uso que fazem, tornando-os mais críticos com relação ao material em questão. Já quanto ao segundo projeto, a partir do qual se pretende entender os vários discursos produzidos na sociedade a respeito dos dois processos que caracterizam a cultura escolar, este trabalho evidencia a visão de ensinar e de aprender que subjazem tais obras didáticas em meio digital e procura mostrar se de fato a consideração desses processos nos denominados livros didáticos digitais de inglês pode configurá-los como exemplares de um gênero discursivo novo. Não se entende aqui que a abordagem de ensino de línguas seja determinada pelo material didático, mas sabe-se que os materiais produzidos para uso em sala de aula são concebidos e organizados com base numa abordagem de ensino em que estão presentes uma visão de língua e linguagem específica (ou de outro conteúdo escolar específico) assim como uma visão de aprender que coaduna com a primeira.

Em termos metodológicos, este estudo caracteriza-se como qualitativo, uma pesquisa descritiva, por se propor a especificar as propriedades e as características de um objeto, suas dimensões enquanto fenômeno (SAMPIERI; COLLADO; LUCIO, 2013), que é o livro didático digital mostrado em páginas de editoras na internet, mais especificamente o livro de inglês. A análise apresentada é de cunho interpretativista com base no referencial teórico apresentado. Atenta-se para elementos que poderiam configurar o livro didático digital como um gênero novo, bem como os objetivos e as formas de uso desse material no contexto de atuação humana de que é próprio: o contexto educacional.

Recorre-se, teoricamente, à visão bakhtiniana de gêneros do discurso, aos conceitos relativos a gêneros discursivos de acordo com a Escola de Sidney, a estudos de alguns autores sobre os chamados "gêneros digitais". Empiricamente, analisam-se exemplares de livros didáticos digitais disponibilizados na internet e dizeres de editores sobre tais recursos didáticos. Tanto teórica quanto empiricamente, adota-se uma posição de criticidade frente à tecnologia digital para fins educacionais como expresso na epígrafe, considerando que ela pode ser benéfica em muitas situações, desnecessária em outras e até mesmo prejudicial se não for usada de maneira consciente. Por fim, são apresentadas as considerações finais retomando a pergunta de pesquisa inicial já apresentada. 
- Livro didático digital de inglês: um gênero novo?

\section{A visão de gêneros de Bakhtin e o livro didático}

Bakhtin (2003) apresenta a noção de gêneros discursivos a partir da noção de enunciado. Este é uma unidade da comunicação discursiva, diferente das unidades da língua (palavras e orações), em cuja produção estão envolvidas condições específicas e finalidades de um campo de atuação. O enunciado, a um só tempo, apresenta conteúdo, estilo e construção composicional. Os discursos são construídos por meio de vários enunciados.

A partir disso, o autor constrói sua visão sobre os gêneros discursivos, os quais ele denomina de tipos relativamente estáveis de enunciados de um campo específico de atividade humana, consequentemente de comunicação e utilização da língua. Nos dizeres do próprio Bakhtin (2003, p. 266),

Uma determinada função (científica, técnica, publicística, oficial, cotidiana) e determinadas condições de comunicação discursiva, específicas de cada campo, geram determinados gêneros, isto é, determinados tipos de enunciados estilísticos, temáticos, e composicionais relativamente estáveis.

Existe uma relação dialética estabelecida nesta visão entre gênero e enunciado. A noção de gênero de Bakhtin é, nos dizeres de Rodrigues (2005, p. 164), "de uma tipificação social dos enunciados que apresentam certos traços (regularidades) comuns que se constituíram historicamente nas atividades humanas, em uma situação de interação relativamente estável", e que normalmente é reconhecida pelos usuários da língua ou de outras formas de significar.

É importante ressaltar, nessa definição, e para a finalidade aqui proposta neste estudo, o caráter relativo dos gêneros discursivos. Bakhtin reconhece a mutabilidade da língua, as mudanças históricas e sociais que acontecem e que se efetuam nos gêneros do discurso. Em se tratando de livros didáticos, eles mudam em termos de composição, conteúdo, estilo, se pensarmos em diferentes abordagens de ensino e de aprendizagem, diferentes edições, recursos tecnológicos e gráfico-editoriais disponíveis em cada época. Mas, não se pode dizer que cada livro didático editado ou reeditado seria um novo gênero visto que o propósito comunicacional continua o mesmo. O livro didático, a cada mudança, ainda pertence à esfera educacional, pois para esse meio ele foi desenvolvido, com objetivo de servir ao ensino e à aprendizagem de conteúdos de uma disciplina, e é reconhecido como tal pelos membros da cultura escolar (professores, alunos, gestores). No caso dos livros didáticos de língua estrangeira, os objetivos do uso desses livros seriam, por parte dos docentes, ensinar a língua, e por parte de alunos, aprendê-la. 
Bakhtin propõe a diferenciação entre gêneros primários e secundários. Os primeiros são aqueles mais simples, construídos nas condições mais imediatas de comunicação, no âmbito da não formalização (RODRIGUES, 2005) sendo exemplos o diálogo, o bilhete, a carta, o relato cotidiano. Já os gêneros secundários são mais elaborados e surgem em condições mais complexas de comunicação e de convívio cultural, no âmbito das ideologias formalizadas e especializadas (RODRIGUES, 2005), como o romance, a peça teatral.

Nessa perspectiva, o livro didático é um gênero secundário, pois está relacionado às situações de comunicação no meio educacional, mas como já dito, não é necessariamente determinador da situação de ensino. O livro didático de inglês é produzido de acordo com diferentes visões de ensinar e de aprender e vem servindo a variados objetivos no contexto escolar: prover conteúdo, atividades e textos; regular, guiar, orientar, controlar, ajudar os processos de ensinar e de aprender. Nele também estão incluídos vários outros gêneros que o constituem. Além de gêneros próprios de todos os livros didáticos (capa, quarta capa, apresentação, sumário, atividade, explicação), os livros didáticos de línguas em geral (e também de outros conteúdos) trazem textos exemplares de outros gêneros pertencentes a diversas áreas de atuação (publicidade, jornalismo, entretenimento, cotidiano, turismo, culinária, dentre outros). Esses textos, ao serem colocados nos livros didáticos, passam a prestar-se a outro objetivo (ensinar), diferente daquele que originalmente caracteriza seu uso na sociedade (divulgar, noticiar, reportar, entreter, etc.).

O trabalho de Buzen e Rojo (2005) é exemplo de uma visão do livro didático de língua como um gênero na perspectiva bakhtiniana. Esses autores analisam a situação do livro didático de português (língua materna) e concluem que, historicamente, ele constitui-se a partir de outros gêneros anteriormente utilizados nos estabelecimentos de ensino - gramáticas, antologias, compêndios; e enquanto gênero, ele incorpora outros gêneros, outras vozes discursivas além da voz do autor, articulando também discursos didáticos diferentes. Acrescento que o mesmo pode ser válido para o livro didático de inglês.

Tratar o livro didático como gênero, para esses autores, tem pelo menos duas implicações: na avaliação e no uso das obras didáticas. Primeiro, na avaliação, essa perspectiva implica tomar um livro didático como obra que tem singularidade, que tem proposta didática específica, e que um livro didático é um enunciado específico, levandose em conta o conjunto da obra e seu projeto didático, não apenas considerando o livro como suporte de atividades, textos e conhecimentos linguísticos. Em segundo lugar, quanto ao uso do livro didático, os autores enfatizam que essa perspectiva pode permitir alunos e professores a escolherem mais conscientemente, relacionarem-se com o 
- Livro didático digital de inglês: um gênero novo?

discurso ali veiculado de maneira mais agentiva, promovendo uma relação mais dialogal com o livro didático do que uma relação de consumo apenas. Essa visão também justifica o trabalho ora apresentado referente ao livro de inglês.

$\mathrm{Na}$ internet podem ser encontrados livros de várias áreas do conhecimento que são denominados pelas editoras como livros didáticos digitais, disponíveis (ainda que em alguns casos o acesso seja restrito) para os alunos e professores, além de ambientes com materiais didáticos especificamente destinados aos docentes. Mas a questão que aqui se coloca é se esses livros configuram um novo gênero discursivo, isto é, se enquanto materialidade discursiva, os denominados livros didáticos digitais são, na perspectiva bakhtiniana, enunciados ligados a um propósito comunicacional diferente, a uma cultura diferente ou específica e diferente daquela do livro didático impresso. No presente artigo, como já dito, procura-se responder a essa questão no que concerne ao livro didático de inglês.

Com base nos conceitos bakhtinianos, Araújo (2016) argumenta que não se pode falar em gêneros digitais, considerando-os típicos da esfera da internet. Para esse autor, com base nas ideias de Bakhtin, gêneros do discurso acontecem em esferas de atuação humana, são organizações discursivas complexas, estão relacionados numa dimensão cultural, não se limitam a uma dimensão geográfica, e a internet não é uma área de atuação humana específica, como seriam o jornalismo, a academia, a religião, a ciência, a publicidade, por exemplo. Nessa ótica, pode-se pensar que o livro didático digital não se configura como gênero digital, mas talvez o que Araújo (2016) chama de remix, decorrente de um processo de reelaboração e inovação de gêneros discursivos em espaços virtuais relativamente livres em que as pessoas não param de inventar. Nessa perspectiva, um texto remix tem vinculação à fonte original e é resultante de diferentes retomadas e releituras dos sujeitos, as quais inspiram novas construções de sentido. Com isso, inferese que o livro didático, impresso ou posto no meio digital, continua servindo a propósitos educacionais, pode ser usado e reusado, pelos sujeitos pertencentes a esse contexto cultural, ali estabelecendo a criação de sentido, logo, poderia ser reinventado. Porém, uma observação primária revela que o fato de um livro didático ter sido colocado na internet não parece mudar as suas condições de produção, nem mesmo sua composição, seu conteúdo, ou o estilo, nem seu propósito comunicacional. Em outras palavras, não parece haver novas construções de sentido na ótica assumida por Araújo (2016). Tal fato será mostrado ao longo do artigo também com base nas ideias sobre gêneros discursivos da Escola de Sidney e com análise de um corpus apresentado adiante. 


\section{O gênero livro didático com base na Escola de Sidney}

A Escola de Sidney de estudos de gêneros do discurso tem embasamento na Linguística Sistêmico-Funcional (HALLIDAY; MATHIESSEN, 2004), que estuda a linguagem na perspectiva de seu uso, considerando-a de natureza sociossemiótica. Assume-se que o uso da linguagem é uma ação social visando a construção de significados, a qual acontece por meio de escolhas em sistemas semióticos. Tais escolhas são fruto da inserção dos sujeitos num contexto social, composto por contextos de situação e de cultura. De acordo com essa teoria, e semelhantemente à visão bakhtiniana, a comunicação humana acontece por meio de textos, e estes são unidades de significado em que são usados recursos semióticos, linguísticos e não linguísticos.

O gênero, por sua vez, surge no contexto de cultura, e é definido como processo social estratificado (em estágios) orientado para objetivos e, por meio desse processo as pessoas organizam suas vidas (MARTIN, 1997). O contexto de cultura, nesta visão, pode ser entendido como o que Bakhtin denomina de campo de atuação humana. Pode-se pensar na cultura escolar ou cultura educacional, por exemplo, contexto para o qual o livro didático é produzido, e no qual ele é usado.

Com relação ao livro didático de inglês, com base em autores adeptos desta escola de estudos de gêneros discursivos, pode-se dizer que este material de ensino é um processo social organizado cujo propósito comunicativo é ensinar inglês. Portanto, ele pertence à cultura escolar. Sua organização se dá na divisão em unidades, lições, páginas, seções, atividades, nas quais novos desdobramentos e objetivos distintos podem ser percebidos, e a cada um desses estágios de realização há um propósito específico ligado ao propósito comunicativo de ensinar a língua. Pode haver uma regularidade, uma padronização, e os conteúdos são postos de maneira semelhante ao longo da obra (SILVA, 2012).

Ao se considerar o uso da linguagem em contexto social, assume-se que este uso é influenciado pelas variáveis do contexto. Assim, um texto, exemplar de um gênero discursivo, está relacionado ao conjunto de valores que realizam as variáveis, de campo (conteúdo; natureza da atividade social), relações (papéis dos interlocutores e relações de poder entre eles), e modo (maneira como a linguagem é usada e veiculada) (HALLIDAY; HASAN, 1989). Estas variáveis estão diretamente relacionadas às três metafunções da linguagem consideradas na Linguística Sistêmico-Funcional: metafunção ideacional (construir e representar experiências dos usuários de um código e sua inserção no mundo conectando ideias de maneira lógica), metafunção interpessoal (estabelecer relações entre os usuários de um código), e a metafunção textual (organizar a mensagem para 
- Livro didático digital de inglês: um gênero novo?

agir no mundo). Percebe-se, então, que metafunção ideacional liga-se ao campo, a metafunção interpessoal às relações, e a metafunção textual relaciona-se com o modo (MARTIN, 1997; EGGINS; MARTIN, 1996). O quadro a seguir mostra, a partir do exposto, uma caracterização do gênero livro didático de línguas (incluído o livro de inglês).

Quadro 1. Caracterização do gênero livro didático de línguas com base na Escola de Sidney

\begin{tabular}{|c|c|l|}
\hline $\begin{array}{c}\text { Variáveis de } \\
\text { situação }\end{array}$ & $\begin{array}{c}\text { Metafunções } \\
\text { da linguagem }\end{array}$ & \multicolumn{1}{|c|}{ Livro didático de línguas } \\
\hline $\begin{array}{c}\text { Campo } \\
\text { (conteúdo) }\end{array}$ & Ideacional & $\begin{array}{l}\text { Tópicos (assuntos) apresentados, conteúdo linguístico, } \\
\text { conteúdo imagético, ideologias, regras de uso da língua, } \\
\text { visão de língua e linguagem. }\end{array}$ \\
\hline $\begin{array}{c}\text { Relações } \\
\text { (teor / estilo) }\end{array}$ & Interpessoal & $\begin{array}{l}\text { Formasimperativas em enunciados de atividades para alunos; } \\
\text { sugestões, orientações ou comandos para professores; } \\
\text { modalizações e graus de certeza sobre determinados tópicos } \\
\text { abordados. }\end{array}$ \\
\hline $\begin{array}{c}\text { Modo } \\
\text { (composição) }\end{array}$ & Textual & $\begin{array}{l}\text { Material impresso com uso de língua escrita padrão, uso de } \\
\text { imagens, organização visando gradação de conteúdo (Dado } \\
\text { - Novo), cores e elementos gráficos usados para separar ou } \\
\text { integrar partes e demarcar elementos iguais ou diferentes. }\end{array}$ \\
\hline
\end{tabular}

Fonte: Elaboração própria

É possível dizer, com base nessa perspectiva, que o livro didático de línguas apresenta uma orientação a objetivos, sendo o maior deles o de ensinar aquele idioma, o que se traduz em outros objetivos: mostrar, promover prática, induzir, promover dedução, avaliar, entre outros. A organização em estágios e elementos pode ser realizada na divisão em unidades, lições, seções e atividades, cada uma com o objetivo de promover ensino e aprendizagem de um conteúdo específico (gramatical, lexical, de mundo, de maneira de agir, modos de falar, pronúncia), desenvolvimento de uma habilidade (falar, ler, escrever e ouvir) em situações diferentes (no cotidiano, academicamente, em situações familiares, em escolas, em competições, em transações comerciais).

Além disso, ao trazer outros gêneros para sua constituição, o livro didático pode ser entendido, nessa perspectiva, como um macrogênero (MARTIN; ROSE, 2006), formado e constituído por outros gêneros. O livro didático de língua estrangeira faz isso e ainda pode ser visto como constituído de outros materiais como softwares, CD-ROM, CD de áudio, DVD, livro de exercícios, livro de atividades extras (SILVA, 2015).

A consideração de gêneros da Escola de Sidney e a perspectiva bakhtiniana dialogam na consideração de gêneros como produtos culturais, atividades sociais de linguagem, modos de significar o mundo. Tanto para Bakhtin quanto para os linguistas 
sistêmico-funcionais, os gêneros são modos de ação e de dizer que regulam, organizam e significam a interação. Pelo exposto, pode-se perceber que o livro didático configura-se como gênero discursivo nessas duas perspectivas. A seguir, observam-se mais de perto os chamados livros didáticos digitais para saber se podem também ser um gênero novo ou não.

\section{Corpus pesquisado}

Antes de descrever o corpus analisado neste artigo e iniciar a análise propriamente dita, é preciso dizer da dificuldade de acesso vivenciada na execução da pesquisa proposta. Como dito na introdução do artigo, houve tentativas de se acessar os chamados livros digitais via códigos disponibilizados para alunos e professores nas capas internas de obras didáticas impressas, o que não logrou êxito. Outra tentativa foi o acesso a sites de editoras que pudessem disponibilizar amostras dos livros didáticos digitais, e para tanto foi usada a ferramenta de busca Google. Quando se clicava nos resultados, em algumas editoras chegava-se à página promocional de uma coleção impressa, sem conexão aparente com o livro didático digital. Após o clique em outro link, chegava-se à página de venda da editora, com versões impressas de livros didáticos diversos. Somente em dois sites de editoras (editora 1 e editora 2 ) foram obtidas informações a respeito de livros didáticos digitais com esse termo, sendo que no sítio de uma delas (editora 2) há apenas textos informativos da editora sobre o que são, o que promovem e como acessá-los. Na página da outra editora (editora 1), foi possível ter acesso a amostras de coleções de livros didáticos de inglês caracterizados como digitais, e nessa mesma página é possível ter acesso a amostras de livros semelhantes de outras disciplinas. Houve dois acessos, um em 2017, outro em 2020. Com isso, foi possível constituir um corpus com amostras de livros produzidos em momentos diferentes. Em nenhum momento verificou-se a disponibilização das obras de modo integral. Retomando o site da editora 2, verificou-se que o texto consultado e analisado em 2017 permanecia o mesmo e novamente não havia acesso a exemplares.

Assim, então, se constitui o corpus de análise desta pesquisa: amostras de cinco livros didáticos digitais da editora 1 editados em momentos diferentes entre 2012 e 2018 (dados primários); e informações sobre o que são, o que promovem e como são livros didáticos digitais conseguidas nos sítios eletrônicos (portais) das editoras 1 e 2 em dois momentos de visualização (dados secundários). No caso das amostras, têm-se partes do primeiro livro de coleções destinadas ao ensino escolar brasileiro: Livro A e Livro B, respectivamente editados em 2014 e 2012 são da consulta ocorrida entre os meses de junho a agosto de 2017, e são destinados a alunos do Ensino Médio e dos anos finais 
- Livro didático digital de inglês: um gênero novo?

do Ensino Fundamental. Livro C, Livro D e Livro E foram editados em 2017, 2016 e 2018, respectivamente, e destinam-se a pré-adolescentes e adolescentes das séries finais do Ensino Fundamental ( $6^{\circ}$ ao $9^{\circ}$ ano), a adolescentes do Ensino Médio, e crianças do Ensino Fundamental $1\left(1^{\circ}\right.$ ao $5^{\circ}$ ano). Os quadros 2 e 3 a seguir sintetizam as informações:

Quadro 2. Amostras de livros didáticos digitais disponíveis para visualização e analisados.

\begin{tabular}{|c|c|c|c|c|}
\hline Livro & Público & $\begin{array}{c}\text { Ano de } \\
\text { publicação }\end{array}$ & $\begin{array}{c}\text { Ano de } \\
\text { visualização }\end{array}$ & \multirow{2}{*}{ Editora } \\
\cline { 1 - 3 } A & Ensino Médio & 2014 & \multirow{2}{*}{2017} & \\
\cline { 1 - 3 } B & Ensino Fundamental 2 & 2012 & \multirow{2}{*}{2020} & \\
\cline { 1 - 3 } C & Ensino Fundamental 2 & 2017 & \\
\cline { 1 - 3 } D & Ensino Médio & 2016 & \\
\hline E & Ensino Fundamental 1 & 2018 & & \\
\hline
\end{tabular}

Fonte: Elaboração própria

Quadro 3. Visualização de sites de editoras com informações sobre livros didáticos digitais

\begin{tabular}{|c|c|}
\hline Sítios eletrônicos & Momentos de visualização \\
\hline Editora 1 & junho a agosto de 2017 e fevereiro de 2020 \\
\hline Editora 2 & junho a agosto de 2017 e fevereiro de 2020 \\
\hline
\end{tabular}

Fonte: Elaboração própria

\section{Análise de exemplares de livros didáticos digitais}

Primeiramente, atenta-se para o fato de que o acesso a este livro digital não é aberto. Verifica-se, no aviso em capas de alguns livros, e nos sites das editoras, que o acesso é para aquelas pessoas (professores e alunos) que já possuem o livro didático impresso. Assim, percebe-se que o chamado livro didático digital de inglês existe apenas como um bônus caso um livro didático impresso seja adotado e adquirido, ou deve ser adquirido à parte, informação não claramente exposta nos sites pesquisados. Este fato neutraliza o argumento apresentado por alguns autores, como Almeida e Nicolau (2013), por exemplo, de que livros didáticos digitais são de grande valia para a sustentabilidade, evitando cortes de árvores para produção de papel e diminuindo gastos de energia. Isso definitivamente não acontece se o acesso ao material digital depende da adoção do mesmo livro didático impresso. 
Ainda assim, ele poderia ser um gênero diferente, mas para tal afirmação, é necessário observar mais detalhadamente o conteúdo/campo, o estilo/teor, e a forma composicional/modo do que se tem disponibilizado na internet. Também é preciso ter em conta se o livro didático digital traz nova organização para a vida dos seus usuários - se ele interfere nas ações de ensinar e de aprender e se ele pertence de fato a outra cultura, outra área de atuação humana específica.

No corpus mencionado, não se detectou qualquer diferença significativa entre o exemplar-amostra de livro didático de inglês dito digital e um livro didático de inglês impresso. Ao se acessar o portal da editora 1, percebeu-se que o que se disponibiliza para conhecimento como livro didático digital de inglês são versões em pdf dos mesmos livros didáticos impressos. As figuras 2, 3 e 4 mostram isso mais claramente.

Na figura 2, mostra-se o início de uma unidade com atividade de pré-leitura e um texto para leitura (aqui capturado apenas um trecho), em que há palavras em azul que indicam links por serem palavras novas para os alunos. Entretanto, ao se usar o mouse do computador e clicar numa dessas palavras, não há o transporte para o link (hipertexto), ou abertura de janelas com explicações ou imagens, como seria possível com o uso da tecnologia do computador. Isso acontece em todas as páginas disponibilizadas e onde há exercícios para os alunos, tem-se nada além da página do livro impresso. O exercício não é executado com auxílio da máquina e o que é disponibilizado pela editora em sua página na internet é apenas uma versão digitalizada do livro impresso (um arquivo pdf) em que não é possível interferir, como visto na figura 3.

As figuras 2 e 3 revelam que a obra em questão não é um livro didático digital, mas sim digitalizado, cuja utilização não seria diferente daquela do mesmo livro, ou outro, em versão impressa. Assim, a organização de vida do professor ou do estudante não muda caso o livro seja digital(izado), pois as atividades terão que ser feitas no ambiente impresso com o caderno, o bloco impresso, a caneta ou o lápis. O mesmo ocorre em algumas páginas do Livro D disponibilizadas no site em 2020, também para o mesmo público-alvo. 
- Livro didático digital de inglês: um gênero novo?

Figura 2. Reprodução de página do Livro A

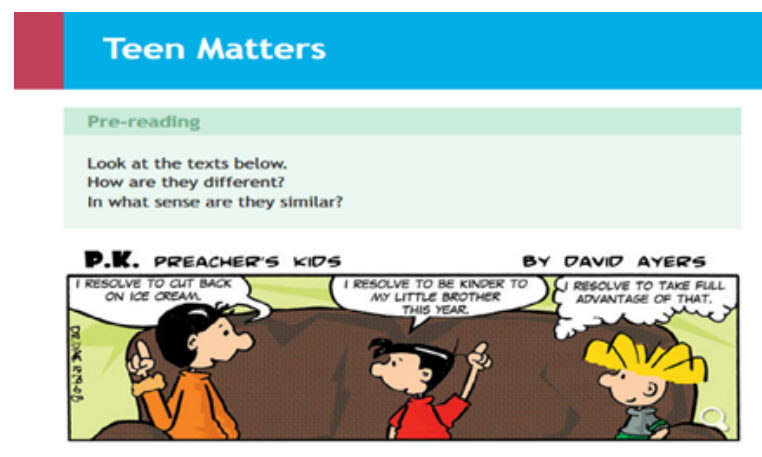

\section{Family}

by Michelle Peters

Family is the strong tie,

That holds you to the ground.

When it seems that you have lost,

All that you had found.

They are the rock that holds you down.

Anen you start to noat away,

Whd they can turn your tife around,

you 'till the end,

And when life treats you rough,

Fonte: http:/

com.br/viewer.html?publicationld=FF-

80808146D2682E0146ED3D27C57F2B\&publicationVersionld=8A0FE00454C33C9E015503085A76422B\&collection=degustacao\#/10. Acesso em: 02 set. 2017

Figura 3. Reprodução de página de exercícios do Livro A em meio digital

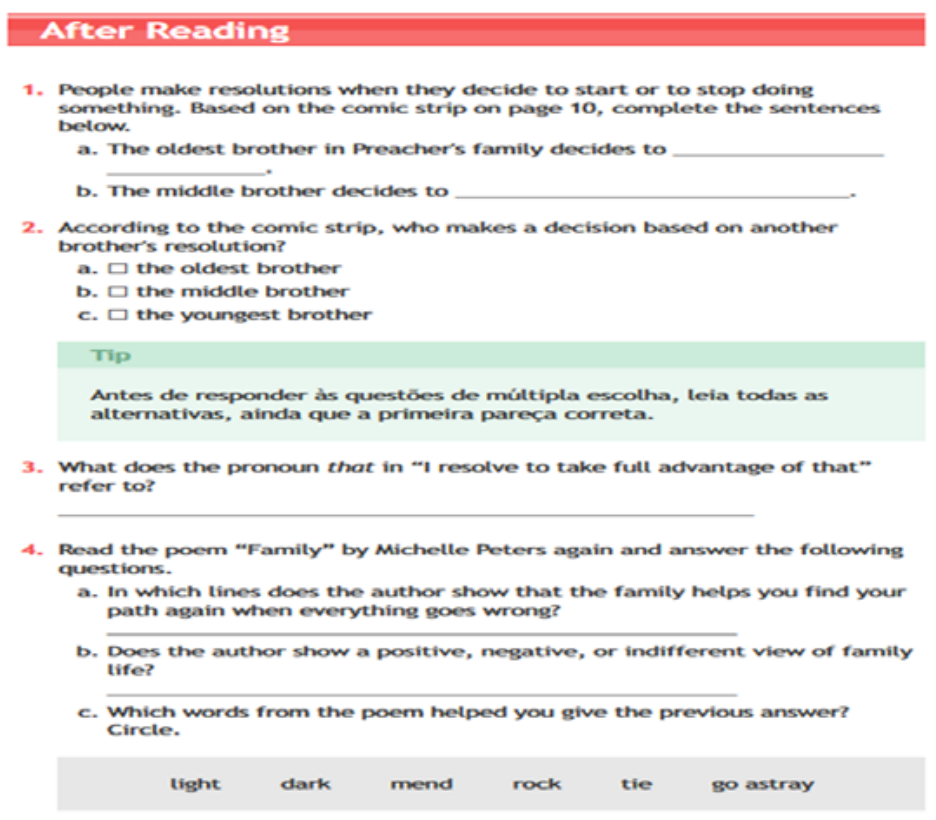

Fonte: http:/

om.br/viewer.tml?publicationld=FF-

80808146D2682E0146ED3D27C57F2B\&publicationVersionld=8A0FE00454C33C9E

015503085A76422B\&collection=degustacao\#/11. Acesso em: 02 set. 2017 
Um pouco diferente acontece com relação aos livros $B, C$ e $E$, bem como em algumas páginas do livro D. Nas páginas disponibilizadas para visualização no meio digital, é possível encontrar momentos em que há uso de recursos tecnológicos, o que permitiria usar e fazer atividades do livro didático digital com auxílio da tecnologia. As figuras a seguir mostram seções em que o aluno pode clicar no sinal de Play (um triângulo) para ouvir a gravação do texto a ser lido (Figura 4), pode fazer atividades de leitura marcando respostas e checando se estão corretas (Figura 5). É possível executar a atividade de compreensão oral e de leitura seguindo a gravação como foi testado no momento da pesquisa. Já as figuras 6 e 7 mostram que há possibilidades de se escrever no arquivo em formato PDF, completando ou marcando nos exercícios disponibilizados, e depois ter acesso a respostas.

Figura 4. Reprodução de exercícios de leitura e compreensão oral de amostras do Livro B

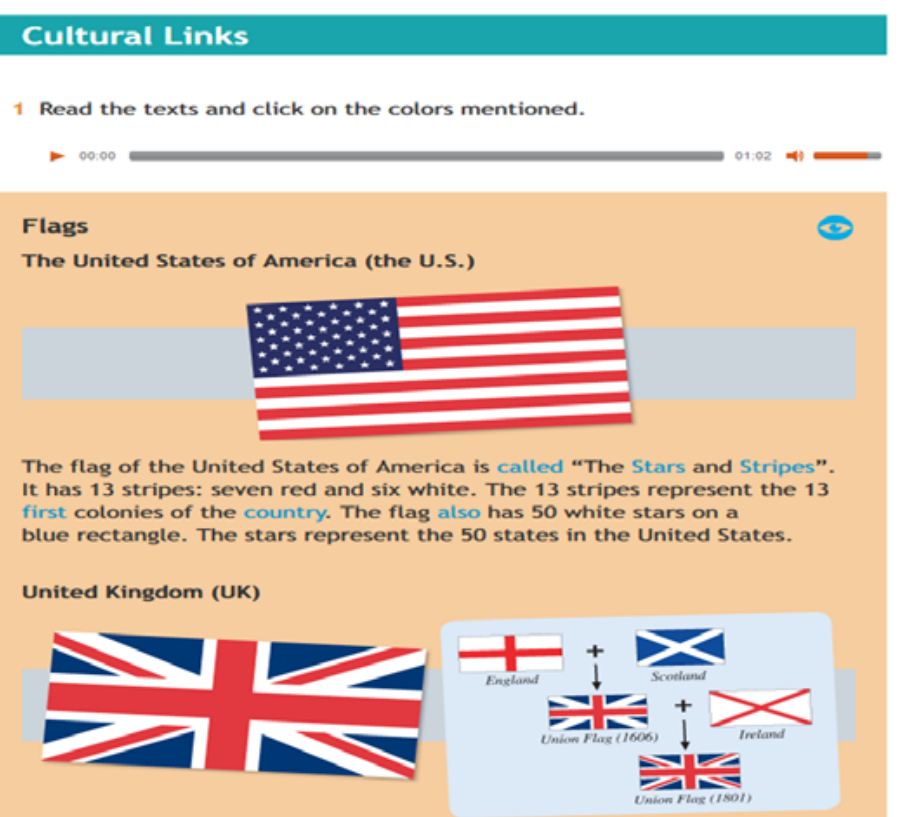

Fonte: http:/

901525FC2BAA76E08\&publicationVersionld=8A0FE00454C33C9E01550307D50B4025\&collection=degustacao\#/26.

Acesso em: 02 set. 2017 
- Livro didático digital de inglês: um gênero novo?

Figura 5. Reprodução de página de exercícios de leitura de amostra do Livro D

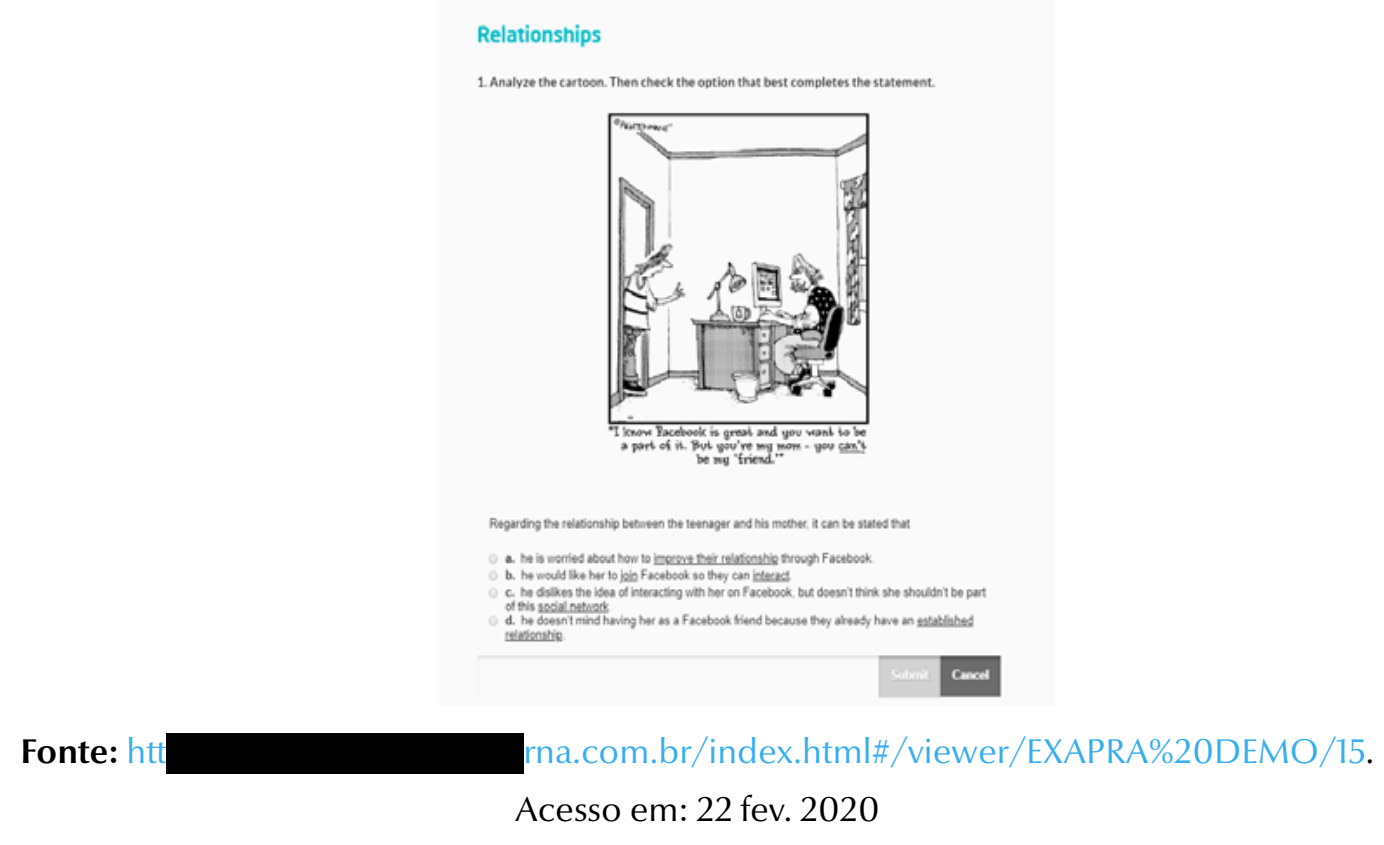

Figura 6: Reprodução de páginas de exercícios do Livro C em meio digital

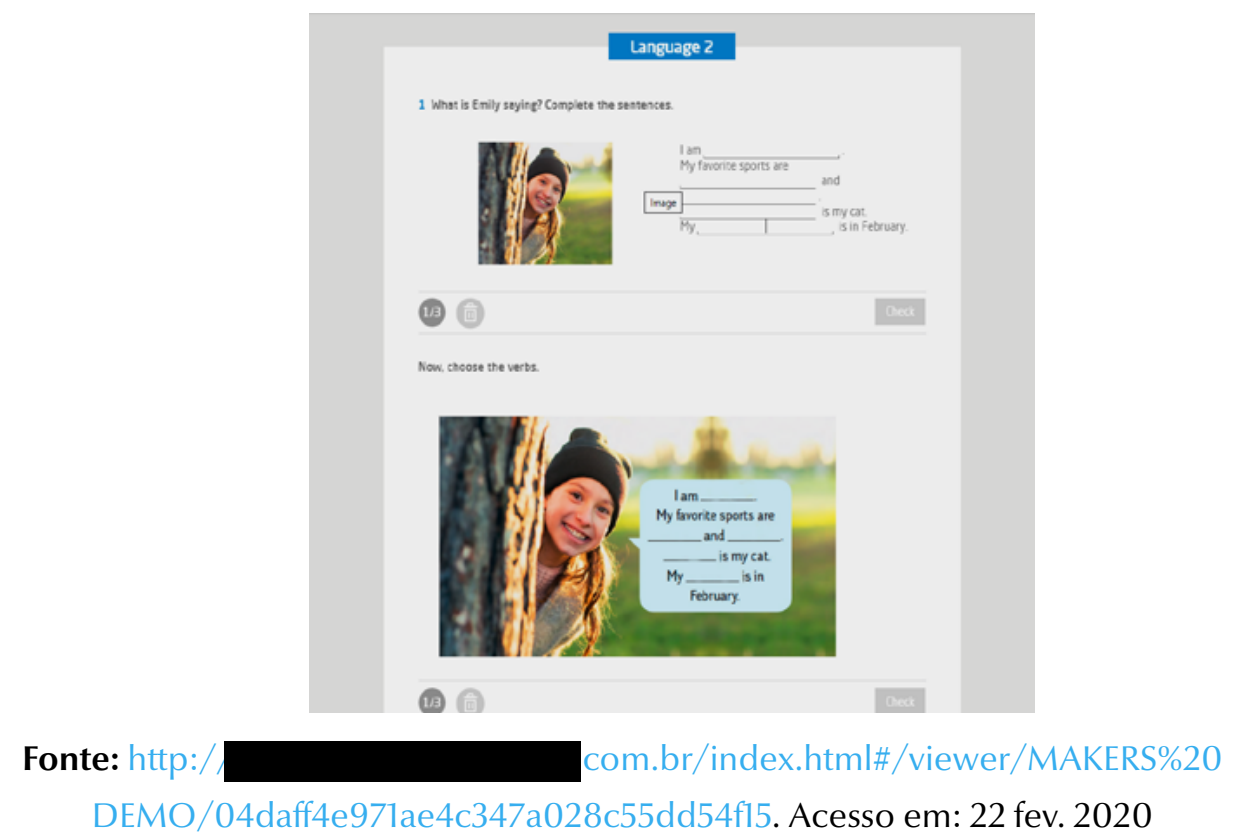


Figura 7. Página de exercícios (Livro B) para alunos completarem em meio digital

\section{Language in Use}
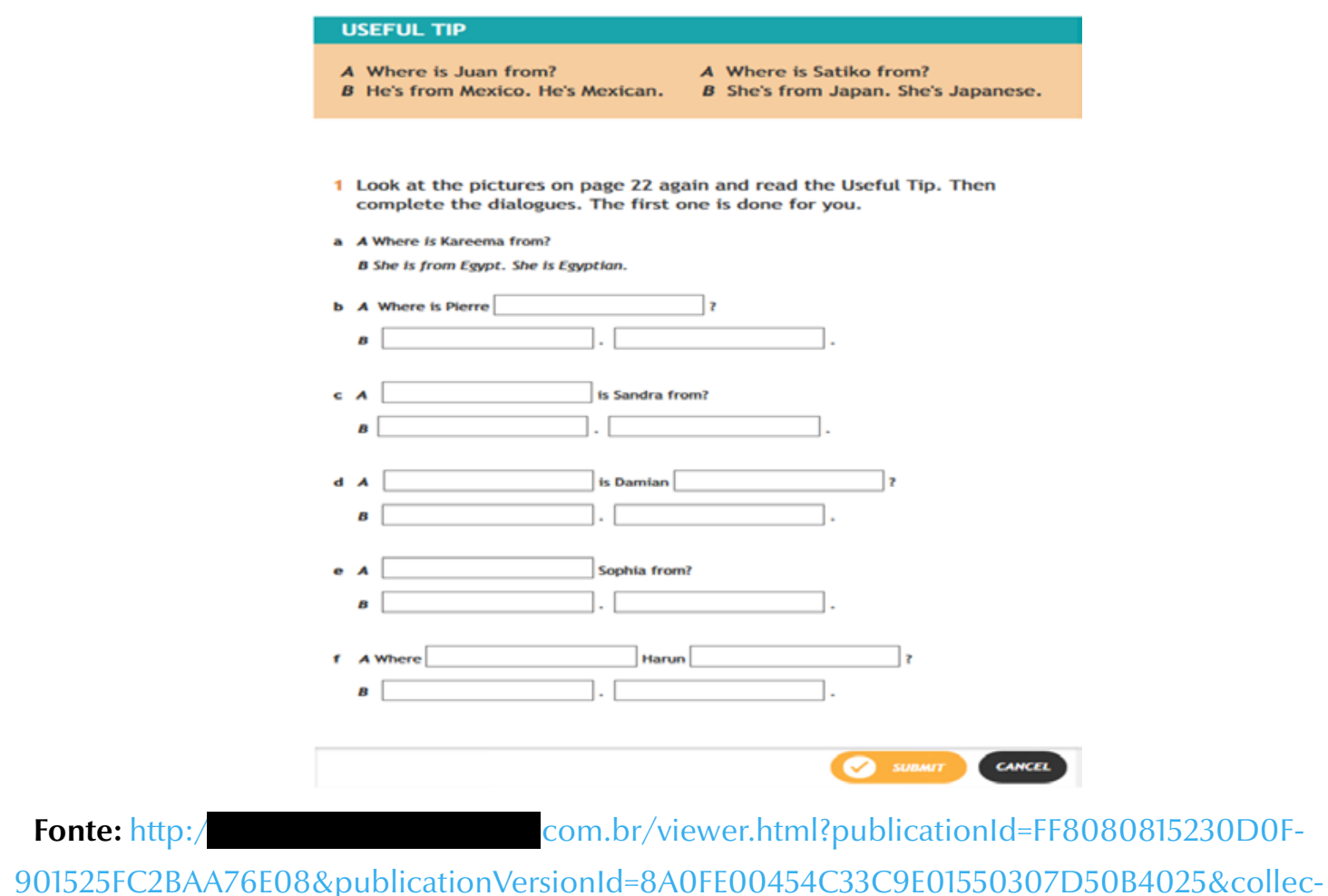

tion=degustacao\#/10. Acesso em: 02 set. 2017

Em todas as imagens, verifica-se que o livro didático digital apresentado pela editora tem a mesma configuração contextual conforme previsto pela Linguística SistêmicoFuncional, sendo diferente, de um título para outro, apenas a possibilidade de se fazer as atividades diretamente com recursos disponíveis pelo computador. O conteúdo (campo do discurso) é o mesmo - linguístico, situacional, tratamento das habilidades, exercícios de gramática e vocabulário. As instruções revelam ações semelhantes às que são ordenadas ou solicitadas num livro impresso: olhar imagens, ler textos, completar lacunas, marcar opção correta, ler, ouvir, responder por escrito, apontar. Os temas tratados são os mesmos de uma versão impressa ou de livros didáticos de inglês em geral: preferências por esportes, nacionalidades, países de língua inglesa, família, tópicos gramaticais. As relações estabelecidas entre o autor (proponente das atividades) com o aluno (usuário) também não mudam, e com isso o estilo não muda, pois há sempre instruções formais com uso do imperativo (ordens) como num livro didático impresso. Mesmo que se argumente em favor da possibilidade de verificação de respostas certas ou erradas, essa ação é possível em alguns livros impressos que trazem chave de respostas ao final, portanto, não parece ser algo tão novo. Quanto à composição textual e o modo, ainda que a disponibilização 
- Livro didático digital de inglês: um gênero novo?

seja pelo computador e a internet (canal), isso não é suficiente para dizer que há mudança significativa. O livro apresentado como digital é versão, reproduzida na tela, do livro impresso original, o layout ainda é o mesmo, as imagens são estáticas como num material impresso, a língua ensinada ainda é apresentada na modalidade escrita (na maior parte do material) ou oral, dependendo do objetivo da atividade.

Em apenas um momento da análise, percebeu-se uso de vídeo numa atividade de compreensão oral, diretamente reproduzida via computador, e que com o livro impresso o professor teria que usar outro recurso tecnológico em sala de aula. Ainda assim, haveria a realização da atividade pelo professor. O mesmo vídeo pode ser disponibilizado ao aluno usuário do livro em diferentes plataformas, até mesmo no site da editora, e não necessariamente precisaria acessar todo o livro digital tendo o impresso.

Dessa forma, a colocação numa mesma página de recursos visuais e sonoros não provoca mudança significativa na organização dos atos de estudar e de ensinar, os quais configuram a cultura escolar. As atividades não mudam em função de uma "nova" proposta de livro didático considerado digital e podem ser executadas na sala de aula ou fora dela da mesma maneira que com o livro impresso e o CD de áudio ou DVD (vídeo), utilizandose papel, caneta ou lápis, ou seja, não necessariamente precisam do computador para serem executadas. Não se verifica uso de atividades com hiperlinks, possibilidade de interação com inteligências artificiais como tutoriais, interação com mais vídeos ou falas mais espontâneas (os áudios são de textos escritos no livro, gravados especificamente em estúdio e os diálogos ou as atividades são controladas). Isso significa que o uso da tecnologia digital é limitado, não se podendo dizer que no livro didático tido como digital há propostas de efetiva exploração do que é próprio do meio digital. Como se vê, a conversão de mídia não depende do livro didático digital para existir em sala de aula ou nos momentos de estudo fora dela; isso é algo possível com recursos tecnológicos como aparelho de som, de vídeo ou o próprio computador, mas não necessariamente o livro didático digital como veiculado.

\section{O que dizem as editoras}

Nas páginas das editoras 1 e 2 na internet (ver figura 8), pôde ser verificado que as mesmas confirmam que o livro didático digital é uma versão digitalizada do livro impresso, o que ajuda a mostrar a não configuração de um novo gênero enquanto material didático. Verifica-se, nos dizeres de uma delas, que há várias versões disponíveis compatíveis com diferentes tipos de máquina e dispositivo como computador e tablet. A editora 2 assim define livros digitais em seu site, incluindo de literatura e didáticos. 
Livros digitais

Versões dos livros da (nome da editora) (didáticos e de literatura) em diversos formatos digitais: PDFs, ePubs, LEDs, iBooks e Apps. Com isso, além de aproveitar todo o conteúdo de seu livro impresso, também é possível acessálo de seu computador ou tablet, enriquecidos com conteúdos adicionais multimídia.

A versão digital(izada) de livros didáticos é anunciada e descrita com diversas possibilidades do que chamam de "interação". Segundo a editora 2 descreve (figura 9), por exemplo, o aluno poderá usar recursos para fazer anotações, marcar trechos importantes, criar palavras-chave para busca, fazer busca por sumário. Essas são ações possíveis de serem realizadas (e comumente são) também no e com o livro didático impresso com recursos tecnológicos mais simples, como o lápis, a caneta e o papel. Mais uma vez, isso mostra que não há mudança na maneira de organizar as ações dos estudantes e possivelmente nem as dos professores, ou seja, o uso de livros didáticos chamados digitais não muda as atividades e a organização da vida desses atores sociais além de não substituir o livro didático impresso, como já dito, e mostrado no site da editora 1 (figura 8). A maneira de estudar prevista com o uso do livro didático digital ainda é a mesma. Mantém-se a cultura escolar como ela tem sido ao longo da história.

Adiante, mostra-se como a editora 2 considera os Livros Educacionais Digitais (LED), descritos na figura 9. 
- Livro didático digital de inglês: um gênero novo?

Figura 8. Apresentação no site da editora 1 dos livros didáticos digitais

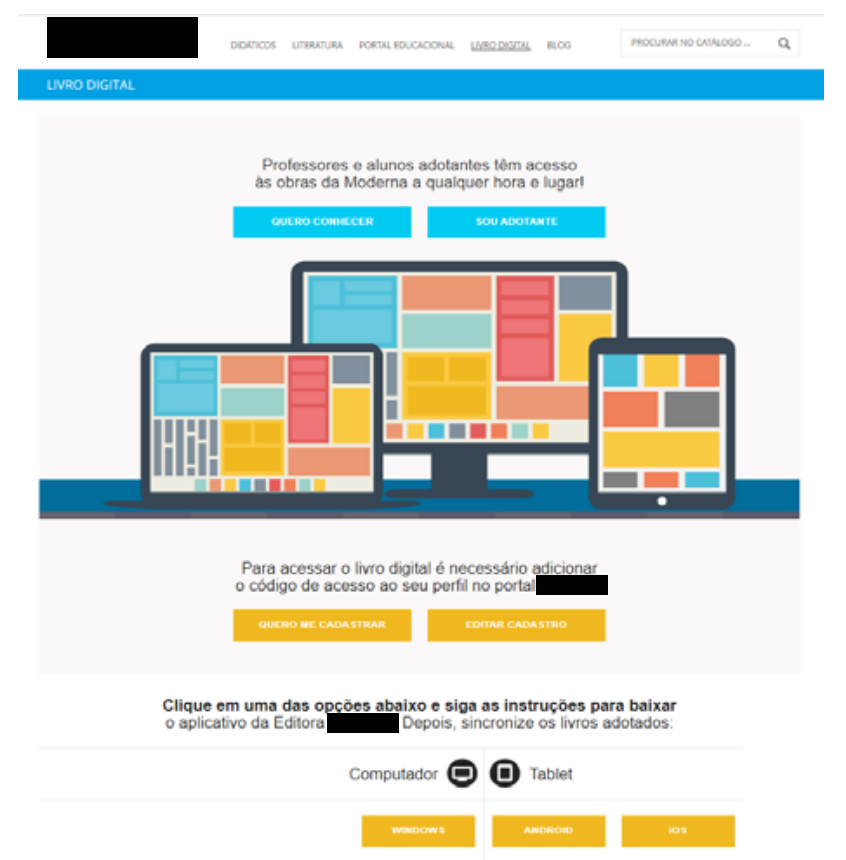

Fonte: https://www

com.br/livro-digital/. Acesso em: 22 fev. 2020

Figura 9. Página da editora 2 na Internet descrevendo livros educacionais digitais

\section{Livros Educacionais Digitais}

Os LEDs (Livros Educacionais Digitais) são versões dos livros impressos que trazem uma série de recursos interativos. Você poderá acessá-los após baixar o Leitor de LEDs e PDFs. Com o leitor instalado você poderá ver seu livro, mas năo apenas uma versăo igual à que você tem no impresso.

É possivel interagir com diversas áreas de um LED. Por exemplo: ao clicar em uma determinada foto, além da imagem impressa, você poderá ver outras tantas imagens relacionadas ao assunto tratado. Ov entāo, ao clicar em um desenho, ele se transforma em uma imagem animada e ganha movimento.

Outros recursos de interaçăo disponiveis nos LEDs sẵo:

$\checkmark$ imagens georreferenciadas

$\checkmark$ imagens com narração

$\checkmark$ imagens tridimensionais

$\checkmark$ imagens panorâmicas

$\checkmark$ minivídeos

$\checkmark$ áudios

$\checkmark$ quizzes

$\checkmark$ textos adicionais

$\checkmark$ anotaçôes do usuário

$\checkmark$ marcador de página e de texto

$\checkmark$ busca por palavra-chave

$\checkmark$ busca por sumário

Fonte: http:/

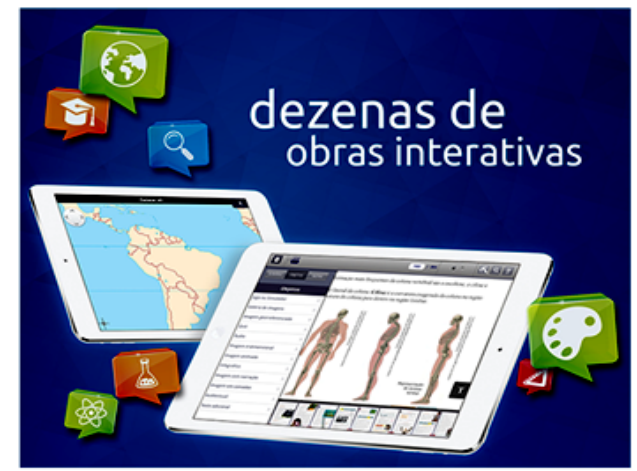

com.br/conheca-livros-digitais-leds.php. Acesso em: 02 set. 2017 e em

22 fev. 2020 
Embora sejam propostas imagens em movimento (vídeos e fotografias animadas), estas foram verificadas em livros didáticos de outras disciplinas, mas não para os livros didáticos de inglês. No entanto, esses recursos não parecem suficientes para se caracterizar o livro didático digital como novo gênero. Esses elementos e a proposta de uso não mudam as atividades sociais de ensinar e de aprender língua com o uso do livro didático: ele ainda serve para tais ações, e esses mesmos recursos elencados pela editora 2 podem ser usados pelo professor em sala de aula ou pelo aluno em outro ambiente acessando sites de vídeo ou de imagens diversas na rede se elas forem mencionadas no material impresso e se houver recurso tecnológico para acesso na escola ou em casa. Vídeos, por exemplo, já podiam ser visualizados desde a época de uso de fitas VHS, ou por meio de DVD. Hoje são disponibilizados na internet. A convergência desses recursos num só dispositivo não gera mudança na e da cultura escolar, nem a organização da vida de alunos e estudantes, principalmente pelo fato de ser disponibilizado como algo a mais além do livro impresso, e somente disponibilizado para quem adota essa versão. Não se muda a maneira de ensinar e nem a de aprender. Assim, o que dizem as editoras em seus sites corrobora a análise empreendida neste artigo e as conclusões decorrentes.

O fato de ser uma versão do livro didático impresso com alguma alteração e ainda por estar na Internet ou ser disponibilizado para download para serem propostas as ações descritas acima, tudo isso não faz com que o denominado livro didático digital de inglês pertença a uma diferente esfera de atuação humana consequentemente a uma nova esfera de comunicação nos termos bakhtinianos. O livro didático impresso de inglês e de outras disciplinas é um gênero próprio do meio escolar e da cultura educacional, e as novidades trazidas pelas editoras ao disponibilizar o livro impresso em versão digital(izada) não promove o que preveem Almeida e Nicolau (2013, p. 8), ou seja, que este recurso didático digital pode "alterar os hábitos de crianças e jovens que não encontram mais no livro didático convencional o estímulo necessário para a aquisição do conhecimento" ou ainda que "a aprendizagem torna-se fácil e divertida, com elementos multimídia capazes de prender a atenção do leitor". Os dados aqui apresentados não sugerem isso, pois as novidades não são muitas. Uma pesquisa para verificar a motivação e facilitação da aprendizagem deveria ser feita com os próprios estudantes, o que os autores também não apresentam, e que está além do objetivo deste trabalho.

\section{Considerações finais}

Ao final da pesquisa, mesmo frente à dificuldade apontada no início desse artigo de acesso a outros exemplares de livros didáticos chamados digitais pelas editoras, podese dizer que a pergunta de pesquisa foi respondida. O denominado livro didático digital 
- Livro didático digital de inglês: um gênero novo?

de inglês não se configura como um novo gênero discursivo, tampouco como remix (ARAÚJO, 2016), pois não parece haver uma reelaboração do gênero quando ele é inserido em ambiente virtual, mas sim apenas o que este autor denomina digitalidade, isto é, uma transferência para a internet em PDF, sem estabelecer diferentes conexões entre alunos e docentes. Sendo uma versão digitalizada disponibilizada na internet para acesso restrito a quem adota o livro impresso, mantendo a mesma configuração contextual, os mesmos elementos constitutivos (conteúdo, estilo e composição), a mesma organização interna, o chamado livro didático digital contribui para a manutenção da organização de vida escolar tradicional e a permanência de uma situação de comunicação já estabelecida. Da maneira como o chamado livro didático digital se apresenta e é apresentado, não se vislumbram mudanças nas relações dos alunos com o livro, dos professores com esses alunos, pois ele não é uma novidade para o ensino. Também não se tem uma organização diferenciada, uso diferente da linguagem ou construção de novos significados que pudessem configurar um modo diferenciado. Como já dito, outras pesquisas, se for possível o acesso ao material, poderiam tratar da adequação desse material pesquisado, mas isso foge ao propósito inicial deste artigo. Pesquisas futuras poderiam averiguar se a colocação do livro didático no meio digital e sua adoção num contexto de ensino e aprendizagem, por si só, provocaria mudanças na cultura escolar, se há efeitos diferentes provocados nos alunos e nos professores.

Em termos da Linguística Sistêmico-Funcional, o conteúdo (campo do discurso) permanece o mesmo - leitura e audição de textos, marcação de respostas corretas, exercícios de compreensão, de vocabulário e gramática nos mesmos moldes que acontece no livro impresso. A relação estabelecida entre autor/aluno por meio das instruções e das atividades ainda é a mesma, ordenando ações que contribuem para o estudo do conteúdo - "leia", "aponte", "ouça", "responda", "marque", "escreva". O modo como a mensagem se organiza permanece semelhante ao do livro didático impresso convencional, numa sequência do mais simples ao mais complexo tanto de atividades, de apresentação de conteúdo e de unidades, estando também uma atividade encadeada à outra numa certa dependência, normalmente usando imagens e língua escrita como modos predominantes. Assim, o campo do discurso, as relações e o modo de uso da linguagem permanecem inalterados se comparados com o livro didático impresso. Consequentemente, o processo social em que as pessoas se engajam de modo a organizar suas vidas não é diferente do que quando se usa um livro didático impresso. Tampouco há mudanças na proposta de utilização ou são propostas atividades com usos de recursos não disponíveis em outro meio diferente do digital. As atividades e ações propostas podem ser executadas independentes do meio digital e isso corrobora a afirmação de Araújo (2016) com relação à inexistência de gêneros discursivos digitais. A internet e a 
tecnologia digital não se configuram uma esfera específica de atividade humana a partir da qual novos gêneros surgiriam. Ao contrário, trata-se de um "ambiente plural de profundo poder de absorção que transmuta para si diversas esferas de atividade humana e, com elas, seus gêneros discursivos" (ARAúJO, 2016, p. 52).

Soma-se que o acesso ao digital, no caso dos livros tratados neste artigo, se faz, muitas vezes, comprando o livro didático impresso. Então, o livro didático digital de inglês não pode ser visto como um novo enunciado no sentido bakhtiniano, mas um enunciado já conhecido divulgado, disponibilizado e acessado de outra maneira - via ambiente digital. As ações feitas com ele, nele, e a partir dele ainda são as mesmas feitas com o livro didático impresso.

Este trabalho enfatiza o livro didático de inglês, mas, acredita-se, apresenta um olhar possível para livros didáticos de outras disciplinas, os quais podem se encontrar numa situação semelhante. Outras pesquisas baseadas em teorias diferentes podem corroborar ou lançar novas questões não tratadas aqui. Uma delas, por exemplo, poderia promover a valorização da voz dos sujeitos usuários, professores e alunos sobre o chamado livro didático digital. Uma análise do que esses usuários dizem sobre esse livro didático digital disponível pode, de certa maneira, corroborar as interpretações aqui defendidas.

Por fim, as interpretações dessa pesquisa levam ao que diz a epígrafe. Há, certamente, e é emergente, a necessidade de uma visão crítica e vigilante por parte de pesquisadores, de formadores de docentes, pesquisadores, gestores, editores e alunos com relação à tecnologia, sobretudo a digital, e o discurso propagado sobre os "benefícios" do chamado livro didático digital.

\section{Referências}

ALMEIDA, F.; NICOLAU, M. A reconfiguração do livro didático em versão digital: uma ideia de sustentabilidade. Revista Temática, ano IX, n. 1, p. 1- 8, jan. 2013. Disponível em: http://www.insite.pro.br/2013/Janeiro/livrodidatico_digital_sustentabilidade.pdf. Acesso em: 21 jul. 2017.

ARAÚJO, J. Reelaborações de gêneros em redes sociais. In: LEFFA, V.; ARAÚJO, J. (org.). Redes Sociais e Ensino de Línguas - o que temos de aprender? São Paulo: Parábola Editorial, 2016. p. 49-64.

BAKHTIN, M. Estética da Criação Verbal. São Paulo: Martins Fontes, 2003. 
- Livro didático digital de inglês: um gênero novo?

BUZEN, C.; ROJO, R. Livro didático de língua portuguesa como gênero do discurso: autoria e estilo. In: COSTA VAL, M. G.; MARCUSCHI, B. Livros Didáticos de Língua Portuguesa: letramento e cidadania. Belo Horizonte: CEALE/Autêntica Editora, 2005. p. 73-118.

DIAS, R.; DELL'ISOLA, R. L.P. (org.). Gêneros Textuais - teoria e prática de ensino em LE. Campinas: Mercado de Letras, 2012.

EGGINS, S.; MARTIN, J. Genres and Registers of Discourse. In: VAN DIJK, T. (ed.)

Discourse: a multidisciplinary introduction. London: Sage, 1996. p. 230-256.

HALLIDAY, M. A. K.; HASAN, R. Language, context and text: aspects of language in social semiotic perspective. Oxford: Oxford University Press, 1989.

HALLIDAY, M. A. K.; MATHIESSEN, C. An Introduction to Functional Grammar. London: Arnold, 2004.

MARTIN, J. R. Analysing genre: functional parameters. In: CHRISTIE, F.; MARTIN, J. R. (ed.). Genre and Institutions: social processes in the workplace and school. London: Cassell, 1997. p. 3-39.

MARTIN, J.; ROSE, D. Genre Relations: Mapping Cultures. London, Oakville: Equinox, $1^{\text {st }}$ gallery, 24/2/2006.

MOTTA-ROTH, D.; HEBERLE, V. M. O conceito de estrutura potencial de gênero de Ruqayia Hasan. In: MEURER, J. L.; BONINI, A.; MOTTA-ROTH, D. (org.). Gêneros teorias, métodos, debates. São Paulo: Parábola Editorial, 2005. p. 12-28.

RODRIGUES, R. H. Os gêneros do discurso na perspectiva dialógica da linguagem: abordagem de Bakhtin. In: MEURER, J. L.; BONINI, A.; MOTTA-ROTH, D. (org.). Gêneros - teorias, métodos, debates. São Paulo: Parábola Editorial, 2005. p. 152-183.

SAMPIERI, R. H.; CALLADO, C. F.; LUCIO, M. P. B. Metodologia de Pesquisa. 5. ed. Porto Alegre: Penso, McGraw Hill, 2013.

SILVA, R. C. Representações do livro didático de inglês: análise dos discursos de produtores e usuários com base na Linguística Sistêmico-Funcional. 2012. Tese (Doutorado em Letras), Pontifícia Universidade Católica do Rio de Janeiro, Rio de Janeiro, 2012a. 
SILVA, R. C. Análise discursiva de apresentações de livros didáticos de inglês em manuais do professor com base na Linguística Sistêmico-Funcional. Revista Pesquisa em Discurso Pedagógico, Rio de Janeiro: IPEL/PUC-Rio, 2012b. p. 1-26.

SILVA, R. C. O livro didático de inglês como um gênero discursivo multimodal promotor de multiletramentos. In: HEMAIS, B. (org.). Gêneros Discursivos e Multimodalidade: desafios, reflexões e propostas no ensino de inglês. Campinas: Pontes, 2015. p. 35-62.

SILVA, R.C. Livro Didático de Inglês - que livro é este? Curitiba: Appris, 2016a.

SILVA, R. C. A quarta capa de livros didáticos de inglês à luz da teoria de gêneros discursivos da Escola de Sidney. Revista do GEL, São Paulo, v. 13, n. 1, p. 157-175, 2016 b.

SILVA, S. Os gêneros discursivos em livros didáticos de inglês como língua estrangeira: representações e implicações pedagógicas. 2006. Dissertação (Mestrado em Letras) Pontifícia Universidade Católica do Rio de Janeiro, Rio de Janeiro, 2006.

VALENTE, V. N. Análise da coleção de livros didáticos para o Ensino Médio PRIME - o ensino das habilidades escritas em LE via abordagem de gêneros. 2012. Dissertação (Mestrado em Estudos de Linguagens) - Centro Federal de Educação Tecnológica de Minas Gerais, Belo Horizonte, 2012.

VIAN JR, O.; LIMA-LOPES, R. E. A perspectiva teleológica de Martin para a análise de gêneros textuais. In: MEURER, J. L.; BONINI, A.; MOTTA-ROTH, D. (org.). Gêneros teorias, métodos, debates. São Paulo: Parábola Editorial, 2005. p. 29-45.

COMO CITAR ESTE ARTIGO: SILVA, Renato Caixeta. Livro didático digital de inglês: um gênero novo? Revista do GEL, v. 17, n. 2, p. 309-333, 2020. Disponível em: https://revistadogel.gel.org.br/

DOI: http://dx.doi.org/10.21165/gel.v17i2.2831

Submetido em: 21/04/2020 | Aceito em: 09/08/2020. 